\title{
Anatomia Funcional e Morfometria dos Intestinos e dos Cecos Pilóricos do Teleostei (Pisces) de Água Doce Brycon orbignyanus (Valenciennes, 1849) ${ }^{1}$
}

\section{José Teixeira de Seixas Filho ${ }^{2}$, José de Moura Brás ${ }^{3}$, Andréa Tassis de Mendonça Gomide ${ }^{4}$, Maria Goreti de Almeida Oliveira ${ }^{5}$, Juarez Lopes Donzele ${ }^{6}$, Eliane Menin ${ }^{7}$}

\footnotetext{
RESUMO - O objetivo do presente trabalho foi estudar a anatomia funcional e a morfometria comparativas nos intestinos médio e posterior e nos cecos pilóricos da piracanjuba (Brycon orbignyanus Valenciennes, 1849) (Characiformes, Characidae, Bryconinae). Foram conduzidos estudos anatomofuncionais e morfométricos nos intestinos médio e posterior e nos cecos pilóricos dessa espécie com hábito alimentar onívoro. Constatou-se, por meio destes estudos, que o padrão de enrolamento das alças intestinais em arranjo em $\mathrm{N}$ apresentou, na segunda classe de tamanho, freqüentes variações no intestino médio, mas foi compatível com os de outras espécies de hábitos alimentares similares. Os estudos da morfometria mostraram que o comprimento total do intestino e das alças intestinais e seus calibres, provavelmente, exercem função específica na absorção dos nutrientes. As relações entre o arranjo das pregas da mucosa e a velocidade de transporte do alimento no intestino médio sugerem que os padrões transversal e oblíquo retardam o avanço do alimento em sentido aboral, possibilitando maior período digestivo e melhor aproveitamento dos nutrientes, contribuindo para a preparação do bolo fecal. O comprimento e o calibre dos cecos pilóricos aumentam com o desenvolvimento do peixe, e o seu padrão de mucosa possui características anatômicas semelhantes às do intestino.
}

Palavras-chave: anatomia, nutrição, peixe de água doce, piracanjuba, teleósteos

\section{Functional Anatomy and Morphometry of the Intestines and of Piloric Cecum of Fresh Water Teleoste (Pisces) Brycon orbignyanus (Valenciennes, 1849)}

\begin{abstract}
The objective of the present work was to study the functional anatomy and the comparative morphometry in the medium and posterior intestines and in the piracanjuba (Brycon orbignyanus Valenciennes, 1849) (Characiformes, Characidae, Bryconinae) piloric cecum. Anatomofunctional and morphometric studies were carried out in the medium and posterior intestines and in the piloric cecum of this specie with omnivore feeding behavior. By means of these studies, it could be concluded that the widding pattern of the intestinal rings, in $\mathrm{N}$ derived, presented, in the second size class, frequent variations in the medium intestine, but was compatible to the other species with similar feeding behavior. The morphometric studies showed that the total intestine length of the intestinal rings and its gauge exert, probably, a specific function on the nutrients absorption. The relations among the mucous fold arrangement and the food transportation speed in the medium intestine suggest that the traversal and obliquous patterns delay the feed progress in the aboral direction, allowing a larger digest period, better feed nutrients profit, contributing for the fecal mass preparation. The length and the piloric cecum gauge increased as fish developed, and the mucous pattern had the same anatomical characteristics as the intestine.
\end{abstract}

Key Words: anatomy, nutrition, fresh water fish, piracanjuba, teleoste

\section{Introdução}

Considerando a grande diversidade das espécies de peixes e a conseqüente diferenciação morfofisiológica, a nutrição de peixes apresenta-se como uma vasta área de estudos, uma vez que estes animais apresentam hábitos e comportamentos alimentares diversos. Apesar de as investigações nesta área acumularem décadas de conhecimentos (BISHOP e ODENSE, 1966; SINHA e MOITRA, 1972, 1975a, b; e CYRINO, 1984), muitos estudos vêm sendo realizados (MENIN, 1988; LOGATO, 1995; GOMIDE, 1996; PEZZATO, 1997; YABE e BENNEMANN, 1997; e MORAES et al, 1997),

\footnotetext{
1 Parte da Tese de Doutorado do primeiro autor apresentada à UFV, financiada pelo CNPq e pela FAPEMIG.

2 Pesquisador da Fund. Inst. de Pesca do RJ - FIPERJ - 24120-191 - Niterói, RJ. E.mail: seixasfilho@yahoo.com.br

3 Professor do Dept. de Matemática/UFV - 36571-000 - Viçosa, MG.

4 Zootecnista, bolsista de DTI da FAPEMIG.

5 Professor do Dept. de Bioquímica e Biologia Molecular/UFV - 36571-000 - Viçosa, MG.

6 Professor do Dept. de Zootecnia/UFV - 36571-000 - Viçosa, MG.

7 Professor do Dept. de Biologia Animal/UFV - 36571-000 - Viçosa, MG.
} 
procurando relacionar as características estruturais, anatômicas e, ou, histológicas do aparelho digestório dos peixes com seus hábitos e comportamentos alimentares.

As relações entre o regime alimentar e as características do aparelho digestório vêm sendo estudadas em outros grupos zoológicos, nos quais a tecnologia já atingiu estádio de controle na formulação e manipulação de rações balanceadas, indispensável na obtenção de resultados produtivos satisfatórios.

Contudo, a nutrição de peixes, principalmente dos Teleostei tropicais, encontra-se longe de estabelecer padrões de exigências que possam ser utilizados pelos nutricionistas.

A literatura ressalta a importância do conhecimento da morfologia do tubo digestório dos peixes, por ser muito variável, relacionando-a com a diversidade dos regimes alimentares e o modo de vida. HIDALGO e ALLIOT (1987) enfatizaram, por exemplo, que o comprimento do tubo digestório repercute de maneira importante nos aspectos quantitativos da digestão e absorção de alimento. Da mesma forma, GALLEGO e RUS (1987) consideraram imprescíndível, antes do aprofundamento no estudo dos distintos mecanismos de absorção intestinal, o conhecimento das características anatomohistológicas do intestino dos peixes.

As características anatômicas do aparelho digestório dos peixes acham-se em estreita dependência com a natureza dos alimentos, as características do habitat, o estado nutricional e o estádio de desenvolvimento do indivíduo, manifestados, especialmente nesse aparelho, por adaptações e modificações. Essas são variações morfológicas provocadas pela ação de fatores do ambiente sobre o organismo, podendo ser de caráter permanente, produzidas na evolução filogenética, como no caso das adaptações, ou de caráter temporário, produzidas no ciclo ontogenético do indivíduo, chamadas de modificações (ANGELESCU e GNERI, 1949). Portanto, é de fundamental importância o conhecimento da biologia das espécies e, em particular, o conhecimento da interligação desses fatores, o que fornece subsídios para melhor compreensão do seu desempenho em seus ecossistemas naturais ou em piscigranjas.

Nesse contexto, o presente trabalho teve como objetivos estudar a anatomia funcional e a morfometria comparativas nos intestinos médio e posterior e nos cecos pilóricos da piracanjuba, (Brycon orbignyanus Valenciennes, 1849) (Characiformes, Characidae, Bryconinae).

\section{Material e Métodos}

Foram utilizados exemplares da piracanjuba, procedentes dos viveiros da Estação de Pesquisas e Desenvolvimento Ambiental de Volta Grande, CEMIG, em Conceição das Alagoas, MG. Os exemplares foram separados em duas classes de tamanho, levando-se em consideração o comprimento-padrão, conforme RICKER (1968). Os 23 peixes que se encontravam entre 14,00 e $18,00 \mathrm{~cm}$ de comprimentopadrão formaram a primeira classe de tamanho, que apresentou médias de peso e comprimento-padrão de $66,10 \pm 3,48$ g e $15,74 \pm 0,21 \mathrm{~cm}$, respectivamente. A segunda classe de tamanho compreendeu a faixa de 23,50 a $29,00 \mathrm{~cm}$, formada por 14 peixes, com média de $380,62 \pm 16,17 \mathrm{~g}$ e $26,14 \pm 0,40 \mathrm{~cm}$ de peso e comprimento-padrão, respectivamente.

Os animais foram coletados, acondicionados em aquários com capacidade para 2.000 litros, sendo submetidos a jejum, por três dias. Após esse período, sofreram imediata contenção fisiológica, segundo MENIN (1994), sendo identificados e fixados em solução aquosa de formol a $4 \% \mathrm{v} / \mathrm{v}$, na qual permaneceram durante todo o período de estudo. Para melhor fixação da mucosa do aparelho digestório, foi executada perfusão, vias oral e anal, com solução aquosa de formol a 4\% v/v (CHAUDRY e KHANDELWAL, 1961) e, para a preservação dos órgãos, foi feita incisão longitudinal ventral, da região gular até próximo ao ânus, ficando, assim, os órgãos expostos à solução fixadora. Os animais receberam ainda injeções intramusculares adicionais do fixador, para melhor preservação dos músculos corporais.

Os estudos anatômicos foram desenvolvidos no Laboratório de Morfofisiologia Animal do Departamento de Biologia Animal do Centro de Ciências Biológicas e da Saúde da Universidade Federal de Viçosa (UFV), Viçosa, MG. Foi considerada a divisão do tubo digestório de BÉRTIN (1958), correspondendo, então, o intestino propriamente dito ao intestino médio e o último segmento, ao intestino posterior. Estes foram subdivididos em segmentos para facilitar o acompanhamento das mudanças anatômicas, em relação à sua disposição na cavidade peritoneal. Assim, cada circunvolução observada na sua trajetória é designada como alça, sendo acompanhada de um algarismo. Portanto, a piracanjuba apresentou nove alças. Foram enfatizados, no estudo anatômico dos intestinos médio e posterior, os seguintes aspectos estruturais: (a) disposição na cavidade peritoneal; (b) padrão da mucosa: orientação das 
pregas da mucosa, estrutura das pregas, presença de anastomoses entre as pregas e distância entre pregas adjacentes; e (c) presença de valva e/ou esfíncter ileorretal.

Após a fixação, foram feitos cortes nos exemplares, segundo AMLACHER (1964), e, com auxílio de microscópio estereoscópico, foi feita a descrição anatômica da disposição dos intestinos médio e posterior na cavidade peritoneal. Em seguida, os intestinos foram dissecados e sua descrição foi feita conforme os planos anatômicos de delimitação: cranial, caudal, dorsal, ventral e laterais direito e esquerdo. Procedeu-se ao estudo do padrão da mucosa dos intestinos e à definição do padrão de enrolamento desses segmentos digestivos na cavidade peritoneal, conforme recomendações de MENIN (1988). O estudo topográfico dos intestinos foi realizado conforme SUYEHIRO (1942).

As medidas de comprimento foram tomadas dos mesmos exemplares utilizados no estudo do padrão da mucosa, com auxílio de paquímetro digital, em milímetros. Foi considerada a distância do início do intestino médio, imediatamente após o esfíncter pilórico ao ânus, em linha reta, como a correspondente ao comprimento dos intestinos médio e posterior. Para as medidas do diâmetro, verificou-se a largura dos intestinos, mensurando-se cada alça intestinal em três posições: caudal, mediana e cranial. Para o cálculo do diâmetro da alça, procedeu-se à média aritmética das três medidas.

As medidas de comprimento e diâmetro dos cecos pilóricos foram tomadas em milímetros, sendo considerada a distância da base de cada ceco pilórico, imediatamente após a inserção com o intestino, em linha reta, até o ápice do saco cego, como a correspondente ao seu comprimento. Uma vez que a piracanjuba apresentou cecos pilóricos monotubulares e outros compostos por um pedúnculo comum na base e nas ramificações no ápice, que variaram em número de duas a seis, o procedimento para a obtenção do comprimento foi incluir o comprimento do pedúnculo comum às ramificações, para torná-los cilíndricos. Este artifício foi utilizado para uniformizar as medidas. Para o diâmetro, mensurou-se a largura, em três regiões dos cecos pilóricos: proximal, média e distal. Nas ramificações, o diâmetro do pedúnculo comum foi dividido pelo número de ramificações e incorporado a elas.

Para expressar matematicamente as medidas, foi utilizado o Coeficiente Intestinal (CI), que expressa a relação entre o comprimento intestinal (intestino médio e posterior) e o comprimentopadrão, segundo BÉRTIN (1958).

Foram calculados a média geral e o erro-padrão para as medidas dos intestinos, com auxílio do Sistema para Análises Estatísticas e Genéticas (SAEG, 1997).

Os segmentos dos intestinos médio e posterior foram ilustrados com auxílio de uma câmara fotográfica e o padrão da mucosa de cada segmento dos intestinos, com auxílio de microscópio óptico binocular (DOCUVAL Carl Zeiss-Jena). Os filmes utilizados foram Gold Ultra 400 da KODAK, coloridos, e as cópias foram feitas em papel fotográfico KODAK F3.

A confecção das pranchas anatômicas das espécies em estudo foi feita com auxílio de microcomputador, por meio de digitalização das fotos no programa PHOTO SHOP 4.0. A diagramação foi realizada no programa POWER POINT.

\section{Resultados e Discussão}

A cavidade peritoneal da piracanjuba, Brycon orbignyanus, é longa e ampla, ovalada na secção transversal cranial e comprimida em sentido caudal. A maioria dos órgãos encontra-se no terço anterior da cavidade peritoneal, onde estão localizados o intestino anterior (esôfago e estômago), as alças 1, 7 e 8 e a porção cranial das alças 2 e 9 do intestino médio, e os cecos pilóricos (Figuras 1A, 2A e 3A). No terço médio, localizam-se a porção caudal das alças 2 e 9 e as alças 3, 4, 5 e 6 do intestino médio; e no terço posterior encontra-se o intestino posterior, que chega ao ânus e se abre anteriormente à nadadeira anal.

A disposição dos órgãos digestórios está diretamente relacionada com a forma da cavidade peritoneal, que, por sua vez, está relacionada com a forma do corpo. Esta disposição é, geralmente, encontrada na maioria dos Teleostei e foi também verificada por MENIN (1988), LOGATO (1995) e GOMIDE (1996), nas espécies estudadas.

Em vista lateral esquerda, o estômago é coberto pelas alças 8 e 9 do intestino médio (Figura 1A). Em vista lateral direita, os cecos pilóricos cobrem grande parte das regiões cárdica e pilórica, ficando exposta apenas a região cecal (Figuras $2 \mathrm{~A}$ a G). A luz das regiões cárdica e cecal é ampla, sendo mais reduzida a da região pilórica, que se estreita gradativamente em direção ao esfíncter pilórico, em que existe acentuada constrição (Figuras $3 \mathrm{~A}$ a G). O intestino médio vem imediatamente após o esfíncter pilórico, limitando-se caudalmente com o intestino posterior. O limite caudal com este último não é anatomicamente de- 
marcado, uma vez que não são encontrados esfíncter e, ou, válvula ileorretal. Assim, o segmento terminal foi denominado intestino posterior, devido à ausência de constrição externa, pouca variação das pregas da mucosa, ausência de esfíncter e valva ileorretal, predominância de coloração, marron claro, da mucosa. Vários autores tiveram o mesmo procedimento, em relação a este segmento, para outras espécies de Teleostei estudadas (BURNSTOCK, 1959; KAPOOR, 1975; MENIN, 1988; AMARAL, 1990; FUGI e HAHN, 1991; LOGATO, 1995; YABE e BENNEMANN, 1997; e MORAES et al., 1997).

Em vistas laterais esquerda e direita e vista ventral (Figuras 1A, 2A e 3A, respectivamente), o intestino médio passa, inicialmente, sob a região de transição entre o esôfago e a região cárdica, flexionando-se, em U, do antímero esquerdo para o direito, formando a alça 1 (n⿳⺈ 1 das Figuras 1A, 2A e $3 \mathrm{~A})$. Tomando sentido caudal, o intestino médio acolase à face direita das regiões cárdica e cecal, constituindo a alça 2 (n⿳⺈ 2 das Figuras 1A, 2A e 3A). Após ultrapassar o fundo cego cecal, flexiona-se dorsoventralmente e segue em sentido cranial ao longo do plano sagital mediano, até alcançar o fundo cego da região cecal (fcc), sendo esta a alça 3 (n⿳⺈ 3 das Figuras 1A, 2A e 3A). Neste ponto do seu arranjo, flexiona-se, quase em ângulo reto, ocupando $\mathrm{o}$ antímero esquerdo, em sentido sagito-laterocranial, formando a alça 4 (no 4 das Figuras 1A, 2A e 3A).

Flexiona-se agora, ventrodorsal e dorsoventralmente, em forma de $\mathrm{U}$, sendo esta a alça 5 ( $\mathrm{n}^{\mathrm{0}} \mathbf{5}$ das Figuras 1A, 2A e 3A), e, em seguida, flexiona-se
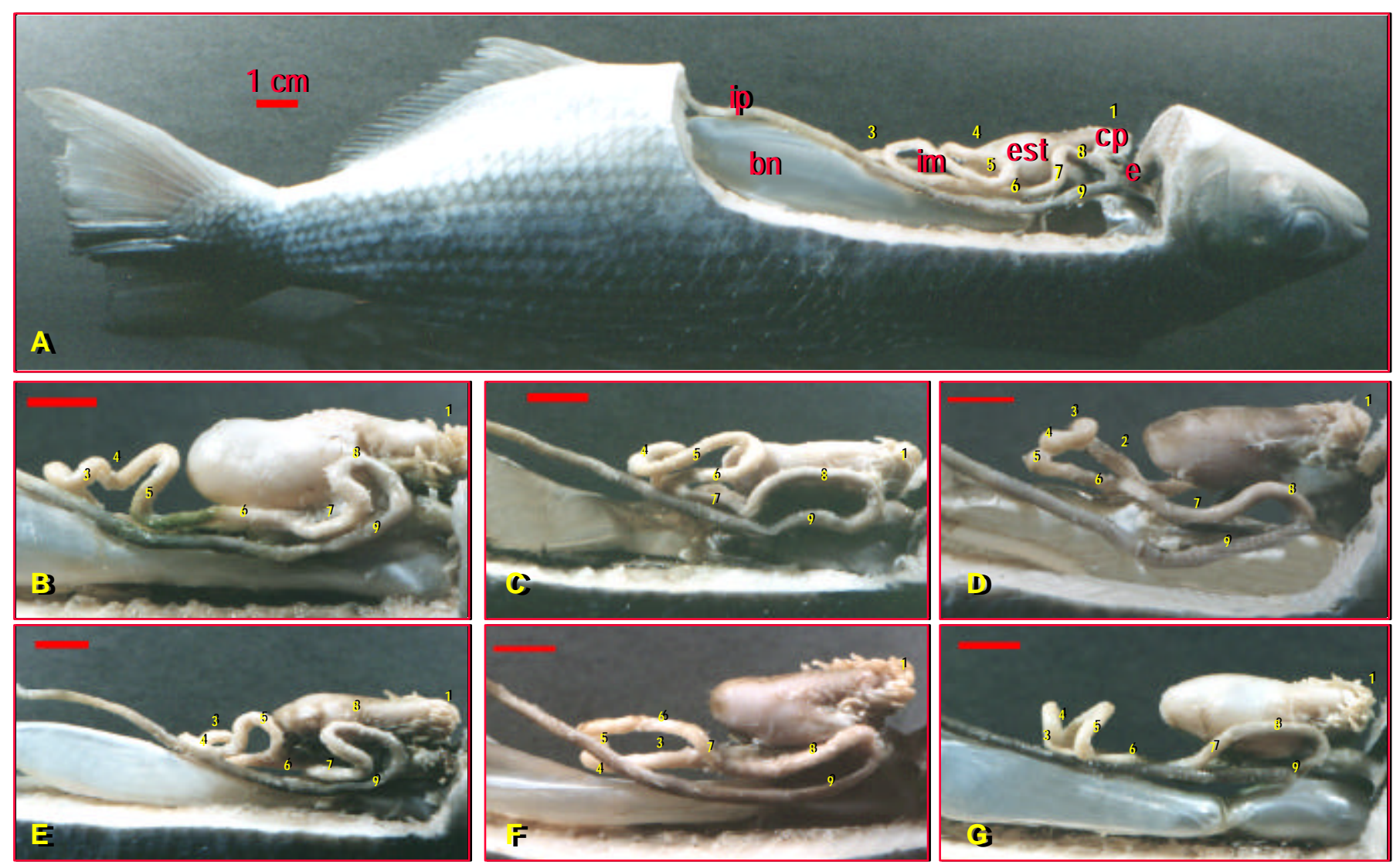

Figura 1 - Brycon orbignyanus, disposição do tubo digestivo na cavidade peritoneal, vista lateral esquerda, sendo: bn - bexiga natatória; $c p$-cecos pilóricos;e-esôfago; est - estômago;im - intestino médio; ip -intestino posterior. Alças intestinais 1 a 9 . B a G, variação do arranjo das alças do intestino médio.

Figure 1 - Brycon orbignyanus, digestive canal arrangment in the peritoneal cavity, left lateral vision, where: bn - natatory bladder; $c p$ - piloric cecum; e - esophagus; est - stomach; im - medium intestine; ip - posterior intestine. Intestinal rings from 1 to 9. B to G, arrangment variation of medium intestine rings. 
latero-sagitalmente, em U. Toma o sentido cranial, inicialmente ao longo do plano sagital mediano e, mais cranialmente, ao longo do parasagital esquerdo, ultrapassando a alça 4, sobrepondo-se ao fundo cego cecal, constituindo a alça 6 (n- 6 das Figuras 1A, 2A e 3A).

Em seguida, circunda-se a porção caudal da parede lateral esquerda da região cecal, forma-se a alça 7 ( $\mathrm{n}^{\mathrm{0}} 7$ das Figuras 1A, 2A e 3A) e flexiona-se em ângulo reto, dorsoventralmente, tomando sentido cranial e acolando-se à parede lateral esquerda das regiões cecal e cárdica, sendo esta a alça 8 (no 8 das Figuras 1A, 2A e 3A). Segue nesse sentido até próximo ao septo transverso, quando se flexiona, pela última vez, ventrodorsalmente tomando sentido laterosagital-caudal, acolando-se à face lateral esquerda das regiões cárdica e cecal, formando a alça 9 (ñ 9 das Figuras 1A, 2A e 3A), ao longo do plano parassagital esquerdo, passando sobre as alças 5, $6 \mathrm{e}$
7, tomando sentido sagital até o ânus, sendo esta porção denominada de intestino posterior (ip) (Figuras 1A, 2A e 3A).

Os cecos pilóricos apresentam-se individualmente evaginados da parede da alça 1, com os mais longos dispostos geralmente na porção média desta alça. Os cecos pilóricos encontram-se voltados em maior número para o antímero direito da cavidade peritoneal, cobrindo a região cárdica e, parcialmente, a região cecal do estômago (Figuras 1, 2 e 3, de A a G).

Esses apêndices intestinais têm aproximadamente o mesmo diâmetro ao longo de sua extensão, adelgaçando-se somente próximo ao ápice, que é arredondado. Na primeira classe de tamanho, com 14,00 a 18,00 cm de comprimento-padrão, eles apresentavam-se na forma cilíndrica ou com duas a três furcações após o pedúnculo basal [Figura 4(detalhe)]; para os exemplares da segunda classe de
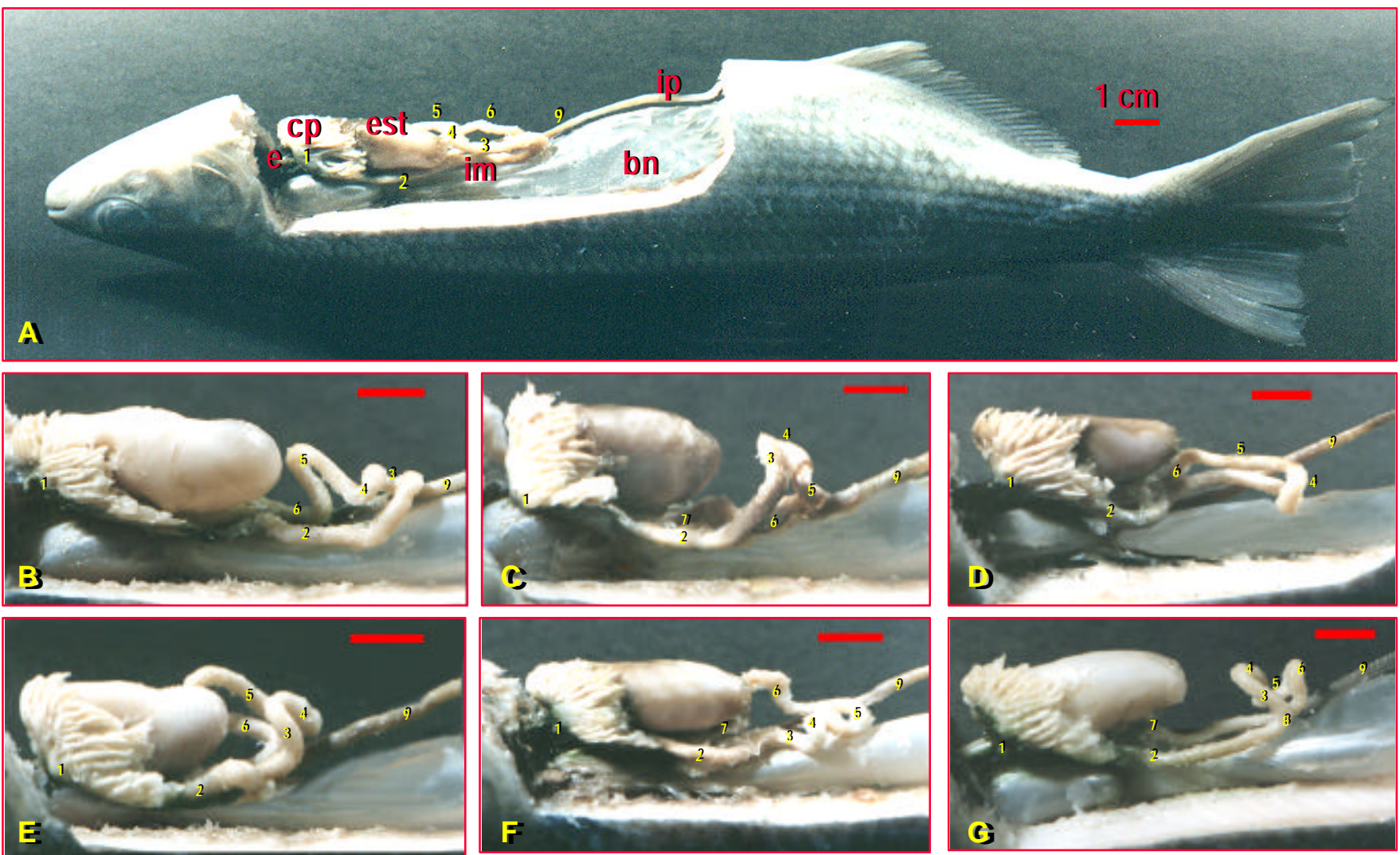

Figura 2 - Brycon orbignyanus, disposição do tubo digestivo na cavidade peritoneal, vista lateral direita, sendo: bn - bexiga natatória; $c p$-cecos pilóricos; e - esôfago; est - estômago; im - intestino médio; ip - intestino posterior. Alças intestinais 1, 2, 3, 4, 5, 6 e 9, de B a G, variação do arranjo das alças do intestino médio.

Figure 2 - Bryconorbignyanus, digestive canal arrangment in the peritoneal cavity, right lateral vision, where: bn - natatory bladder; $c p$ - piloric cecum; e - esophagus; est - stomach; im - medium intestine; ip - posterior intestine. Intestinal rings 1, 2, 3, 4, 5, 6, and 9, from $B$ to $G$, arrangment variation of medium intestine rings. 
tamanho, com 23,50 a 29,00 cm de comprimentopadrão, observou-se a formação de até seis furcações [Figura 5(detalhe)]. Estruturas similares foram relatadas por MENIN (1988) para a espécie carnívora, Hoplias malabaricus. O mesmo foi observado por LOGATO (1995) em Piaractus mesopotamicus, espécie onívora. MAGNAN e STEVENS (1993) observaram, em Salvelinus fontinatis, mudanças morfológicas nos cecos pilóricos desta espécie, em resposta a diferentes qualidades de alimentação, como baixa digestibilidade, apresentando intestinos e cecos pilóricos de maior tamanho, quando comparados àqueles de exemplares que receberam alimentos mais digestíveis.

Os exemplares da primeira classe de tamanho apresentaram arranjo do intestino médio com variações individuais mínimas, podendo, portanto, ser considerado como padrão para a espécie. Este arranjo foi observado em alguns exemplares da segunda classe de tamanho, conforme ilustrado em vistas laterais esquerda e direita (Figuras 1A e 2A) e ventral (Figura 3A).

Para a maioria dos exemplares da segunda classe de tamanho avaliados, pode-se observar que, quanto à disposição das alças intestinais, o segmento inicial do intestino médio (alça 1 e porções cranial e mediana das alças 2 e 9) e o intestino posterior não se alteram. Quando se inicia a variação do arranjo em N, a disposição das alças 5 a 8 varia entre os diferentes exemplares dessa classe de tamanho (Figuras 1B, C, D, E, F e G; 2B, C, D, E, F e G; e 3B, C, D, E, F e G).

Alguns autores procuraram relacionar o arranjo
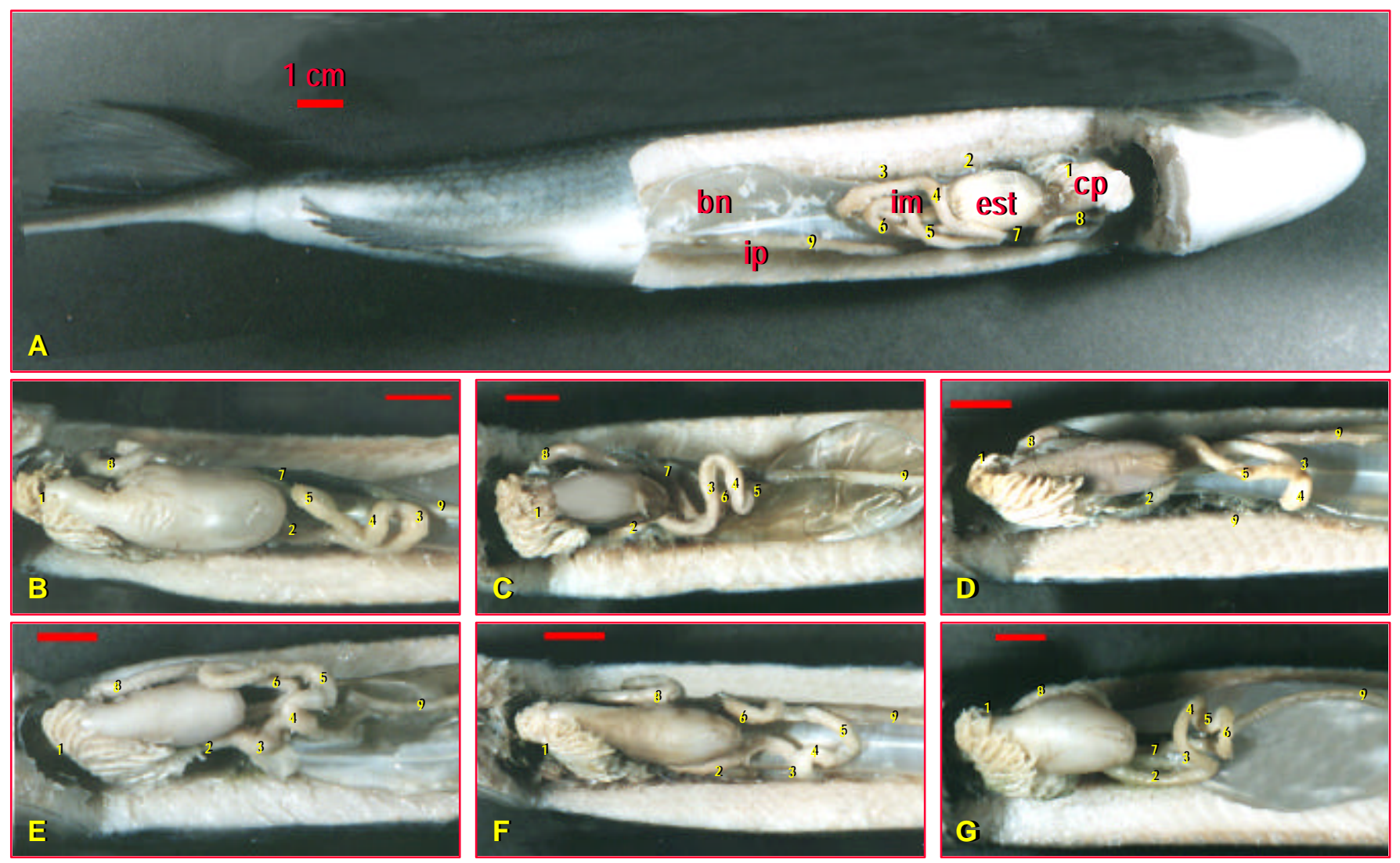

Figura 3 - Brycon orbignyanus, disposição do tubo digestivo na cavidade peritoneal, vista ventral, sendo: bn - bexiga natatória; cp - cecos pilóricos; est - estômago; im - intestino médio; ip -intestino posterior. Alças intestinais 1 a 9. B a G, variação do arranjo das alças do intestino médio.

Figure 3 - Brycon orbignyanus, digestive canal arrangment in the peritoneal cavity, central vision, where: bn - natatory bladder; $c p$ - piloric cecum; e - esophagus; est - stomach; im - medium intestine; ip - posterior intestine. Intestinal rings from 1 to 9. B to G, arrangment variation of medium intestine rings. 
Rev. bras. zootec.

das alças intestinais com os hábitos alimentares dos peixes. As adaptações do intestino, desde o comprimento e o arranjo na cavidade peritoneal até a estrutura da mucosa, é um dos aspectos mais estudados, em nível anatômico, quanto às interações entre o ambiente, o regime alimentar e o aparelho digestório dos peixes (FUGI e HAHN, 1991; MORAES et al, 1997).

$\mathrm{Na}$ espécie estudada no presente trabalho, o arranjo das alças intestinais foi bastante definido, o plano geral do intestino médio e do reto foi mantido, mesmo para os exemplares da segunda classe de tamanho, que apresentaram, além do arranjo padrão do intestino médio, outras formas.

SUYEHIRO (1942) concluiu que o arranjo das alças intestinais é geralmente semelhante para um determinado gênero e difere entre os gêneros de uma mesma família. Parte de suas afirmações está de acordo com o observado entre os exemplares da piracanjuba,
Brycon orbignyanus, neste estudo, que apresentaram arranjo intestinal muito semelhante ao deBrycon lundii (MENIN, 1988). A espécie mencionada no presente estudo deve estar adaptada para uma alimentação com valores intermediários entre o arranjo intestinal de peixes ictiófagos e o dos herbívoros ou dos iliófagos.

Para os exemplares da segunda classe de tamanho da piracanjuba, as variações individuais acontecem sempre da terceira à oitava alça do intestino médio, que também se estendem mais ou menos caudalmente na cavidade peritoneal. Pode-se notar que as referidas variações proporcionaram acentuada curvatura nas alças intestinais, logo após cada circunvolução, sugerindo que essas modificações retardam a passagem do alimento, aumentando, dessa forma, a absorção dos nutrientes, sendo que essas variações não ocorreram no intestino posterior. SUYEHIRO (1942) também verificou que as pe-

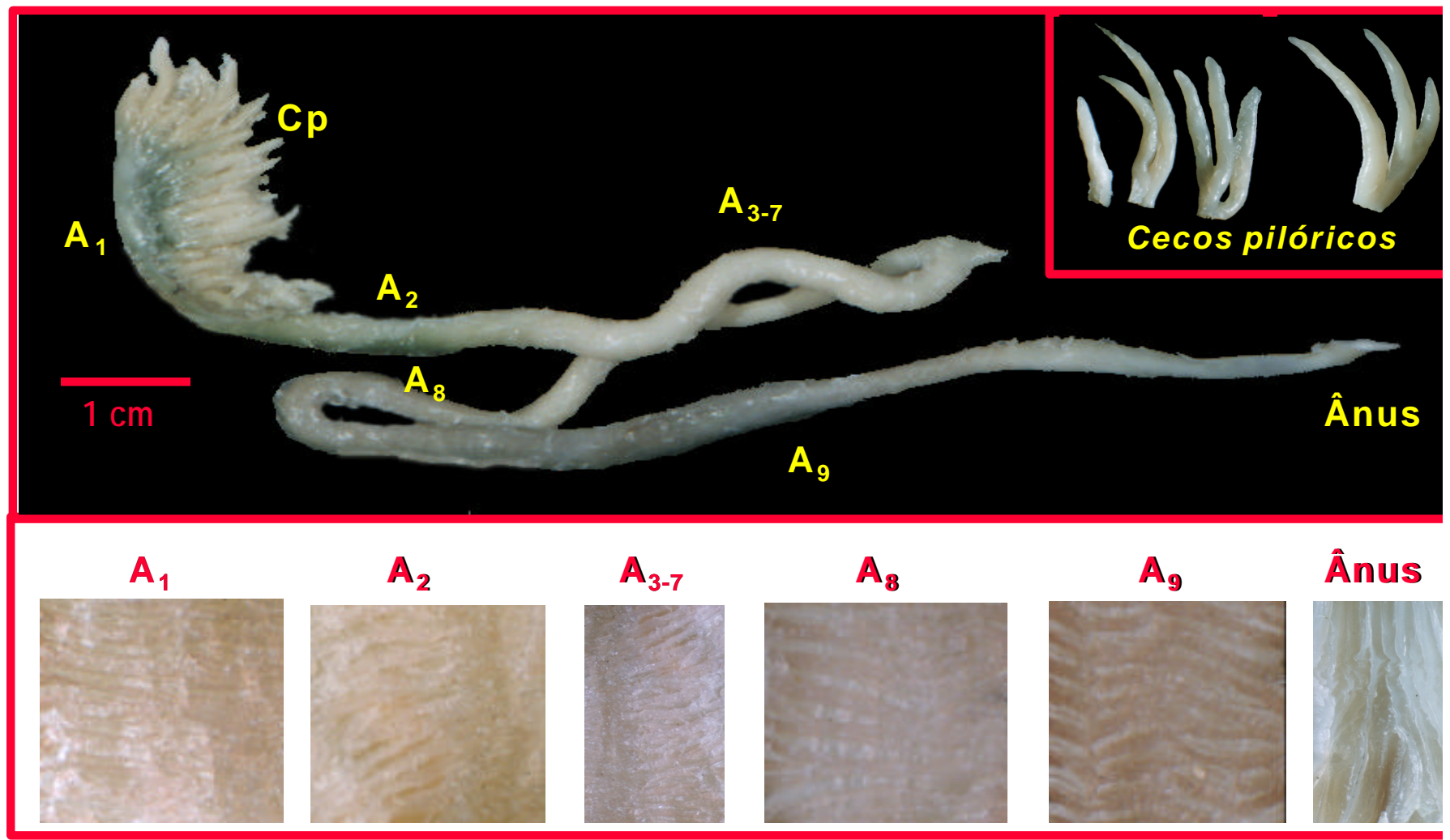

Figura 4 - Brycon orbignyanus (14,00 a 18,00 cm), intestinos médio e posterior, vista lateral esquerda e detalhe do padrão da mucosa das alças intestinais, sendo: an - ânus; $c p$ - cecos pilóricos. $A_{1}, A_{2}, A_{3}, A_{4}, A_{5}, A_{6}, A_{7}, A_{8}$ e $A_{9}=$ alças intestinais 1 a 9. Aumento: $A_{1}$ a $A_{9}-140$ X e ânus - $209 X$.

Figure 4 - Bryconorbignyanus (14.00 to $18.00 \mathrm{~cm}$ ), medium and posterior intestines, left lateral vision and detail in the intestinal rings mucosa standard, where: an - anus; $c p$ - piloric cecum. $A_{1}, A_{2}, A_{3}, A_{4}, A_{5}, A_{6}, A_{7}, A_{8}$ and $A_{9}=$ intestinal rings from 1 to 9. Increase: $A_{1}$ to $A_{9}-140 X$ and anus - $209 X$. 
quenas diferenças acontecem, em geral, no intestino médio.

Para os exemplares da primeira classe de tamanho, as pregas da mucosa das alças 1 a 9 são circulares, dispostas transversalmente às paredes intestinais, pouco espessas e estreitas, com bordas livres ligeiramente onduladas e dispostas muito próximas umas das outras. No intestino posterior, as pregas mantêm essa mesma disposição, sendo apenas um pouco mais espessas e mais largas que as alças do intestino médio. Próximo ao ânus, as pregas têm direção longitudinal, sendo paralelas, pouco espessas e estreitas. O padrão das pregas da mucosa ao longo dos intestinos médio e posterior pode ser observado mesmo externamente, a olho nu, uma vez que suas paredes são muito delgadas.

Não foi observada variação do diâmetro e nem existem outros aspectos anatômicos que justifiquem o fato de denominar a última alça intestinal de reto, posto que a estrutura da mucosa ao longo dos intestinos médio e posterior é muito semelhante e não ocorrem valva e, ou, esfíncter ileorretal que limitem caudalmente o intestino médio (Figura 4).

Para os exemplares da segunda classe de tamanho, ao longo dos intestinos médio e posterior, ocorrem pregas transversais (alças 1 a 7 ) e obliquamente dispostas às paredes intestinais (alças 8 e 9), cuja estrutura é característica nas alças 1,2 a 7 (formas semelhantes), 8 e 9 , tendo-se observado nesta última diferenças de estrutura, mesmo entre as suas porções cranial, média e caudal.

As pregas da mucosa da alça 1 são circulares, longas, dispostas transversalmente às paredes intestinais, muito espessas e largas, com bordas livres não-

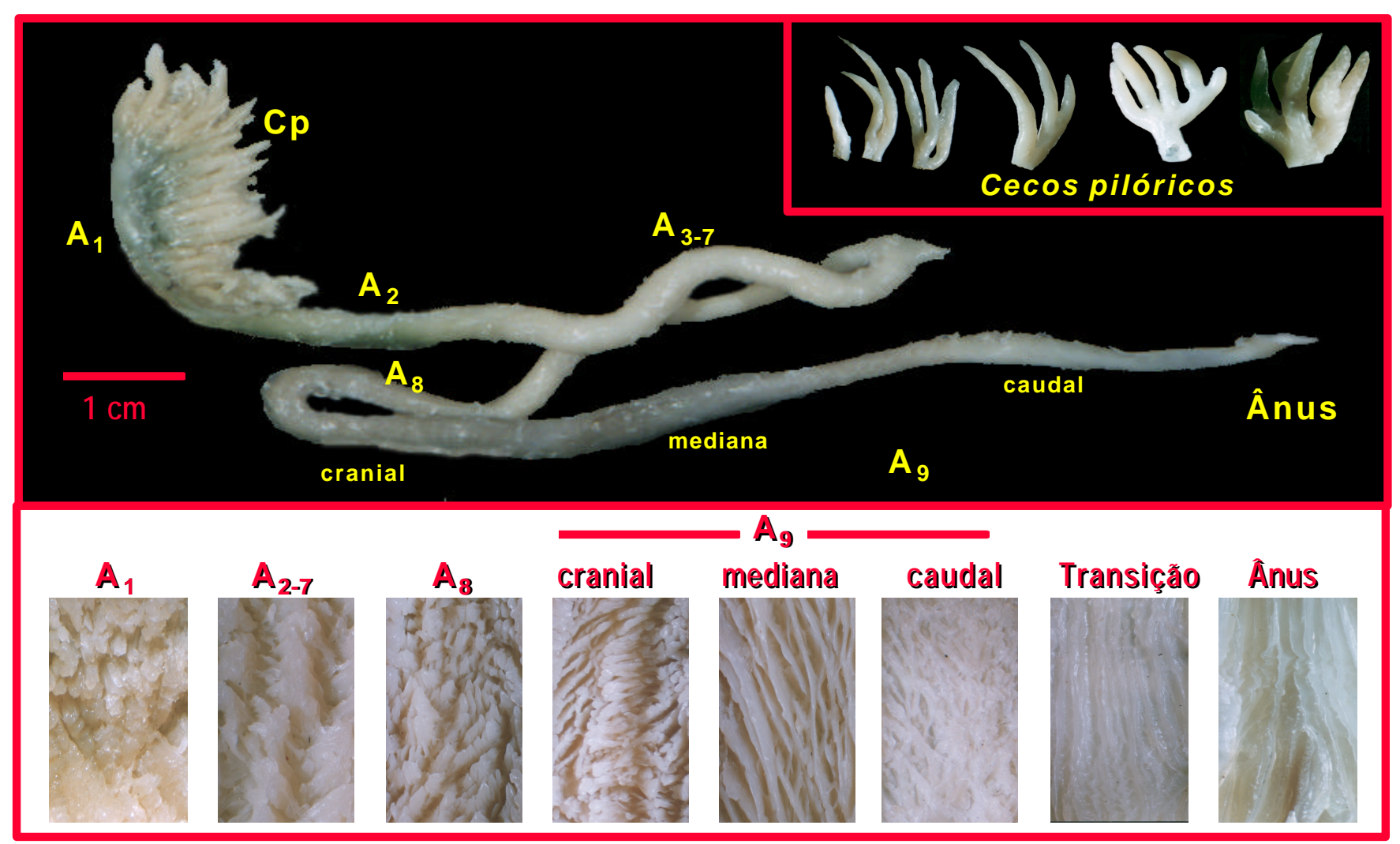

Figura 5 - Brycon orbignyanus (23,50 a 29,00 cm), intestinos médio e posterior, vista lateral esquerda e detalhe do padrão da mucosa das alças intestinais, sendo: an - ânus; $c p$ - cecos pilóricos. $A_{1}, A_{2}, A_{3}, A_{4}, A_{5}, A_{6}, A_{7}, A_{8}$ e $A_{9}=$ alças intestinais 1 a 9. Aumento: $A_{1}$ a $A_{9}$ (mediana e transição) e ânus - 209X; $A_{g}$ (cranial e caudal) $105 X$.

Figure 5 - Bryconorbignyanus (23.50 to $29.00 \mathrm{~cm}$ ), medium and posteriorintestines, left lateral vision and detail in the intestinal rings mucosa standard, where: an - anus; $c p$ - piloric cecum. $A_{1}, A_{2}, A_{3}, A_{4}, A_{5}, A_{6} A_{7}, A_{8}$ and $A_{9}=$ intestinal rings from 1 to 9. Increase: $A_{1}$ to $A_{9}$ (Medium and transiction) - $140 X$ and anus - $209 X ; A_{g}$ (cranial and tail). 
onduladas e dispostas próximas umas das outras, com sulcos profundos entre si. Das alças 2 a 7 , observaram-se pregas longas, dispostas transversalmente, com bordas arredondadas, menos espessas que as da alça 1, com sulcos profundos em sentido longitudinal entre as "fileiras" de pregas. A alça 8 apresentou pregas em sentido oblíquo, longas, estreitas, com bordas arredondadas livres. Na porção cranial da alça 9, as pregas são longas na porção sagital do segmento e mais curtas nas porções laterais esquerda e direita, estreitas e pouco espessas, obliquamente dispostas à parede intestinal, com sulcos profundos entre as pregas. Na porção média, as pregas são curtas, mais espessas que nas alças anteriores, intensamente anastomosadas e dispostas em sentido oblíquo à parede intestinal. Na porção caudal, as pregas são pouco espessas e estreitas, ainda intensamente anastomosadas, porém com menor altura que as da porção anterior. Na região de transição, as pregas tornam-se bruscamente longitudinais, paralelas, mais curtas, em relação à porção anterior, com pequena sinuosidade na sua porção caudal, mantendo essa estrutura até o ânus (Figura 5).

ANGELESCU e GNERI (1949) procuraram relacionar a estrutura da mucosa intestinal com os processos fisiológicos de digestão e absorção, afirmando que a região com as pregas mais complexas estaria mais envolvida com os processos absorptivos, em virtude do aumento da área efetiva para a absorção dos nutrientes. Observações semelhantes foram feitas por FUGI e HAHN (1991), LOGATO (1995), MORAIS e BARBOLA (1995) e GOMIDE (1996).

Essas relações podem ser mais bem evidenciadas na segunda classe de tamanho da piracanjuba, em que os dois primeiros terços intestinais se apresentam com a mucosa extremamente desenvolvida, estando, provavelmente, mais relacionada com os processos de absorção dos nutrientes.

As pregas da mucosa dos cecos pilóricos de Brycon são semelhantes, em aspecto e estrutura, às do intestino médio desta espécie. Essas pregas aumentam de espessura e anastomosam-se perto do ápice dos cecos. Assim, a luz cecal estreita-se em direção ao ápice.

Os resultados do comprimento total, das alças, do calibre dos intestinos médio e posterior e do coeficiente intestinal encontram-se na Tabela 1. Houve diferença significativa $(\mathrm{P}<0,05)$ do comprimento total e das alças intestinais entre os exemplares da primeira e segunda classes de tamanho. Pode-se observar que, para as duas classes de tamanho, a porcentagem de cada alça intestinal em relação ao comprimento total do intestino foi semelhante, apresentando crescimento proporcional ao aumento do tamanho dos intestinos médio e posterior, em razão do desenvolvimento do peixe. Para as duas classes de tamanho, o menor e o maior comprimento foram observados nas alças 1 e 9 , respectivamente $(\mathrm{P}<0,05)$, em relação às outras alças; a alça 2 apresentou o segundo maior comprimento.

Para os exemplares da primeira classe de tamanho, não houve diferença significativa no calibre da primeira até a nona alça, apesar de haver diferença percentual de $18,12 \%$ da primeira para a última alça. Por outro lado, os exemplares da segunda classe de tamanho apresentaram diferença significativa $(\mathrm{P}<0,05)$ no calibre intestinal. A alça 1 apresentou o maior calibre, mostrando redução significativa $(\mathrm{P}<0,05)$ nas alças $2,3,4,5$ e 6 . O calibre das alças 7 e 9 não apresentou diferença significativa em relação ao calibre da alça 4 , assim como o da alça 8 não diferiu do da alça 3; e a última alça apresentou diferença percentual, no calibre, de $23,90 \%$ em relação à primeira alça.

No presente estudo, verificou-se que não houve diferença no calibre dos intestinos entre as duas classes de tamanho, apesar de os exemplares da primeira classe apresentarem calibre médio dos intestinos de 2,59 $\mathrm{mm}$ e os da segunda, de 2,88 $\mathrm{mm}$. Contudo, o calibre das alças intestinais é homogêneo, para a primeira classe de tamanho, podendo-se constatar influência das estruturas das pregas da mucosa intestinal, uma vez que se apresentaram mais delgadas que as dos exemplares da segunda classe, que mostraram maior calibre para a primeira alça intestinal; a estrutura das pregas da mucosa apresenta-se mais espessa nas outras alças do intestino médio, que apresentaram variadas formas nas circunvoluções, com redução gradual de calibre em direção ao intestino posterior, em que as pregas são mais delgadas e espaçadas.

Os estudos da morfometria do calibre intestinal são semelhantes aos encontrados por LOGATO (1995), o qual observou, em Piaractus mesopotamicus, espécie de hábito alimentar também onívoro, que o diâmetro do intestino médio é maior na sua porção inicial, da qual se evaginam os cecos pilóricos, mantendo-se, após essa porção, relativamente constante. Já para o intestino posterior, ocorreu redução gradativa de diâmetro até o ânus. MENIN (1988), estudando espécies onívora e carnívora, e GOMIDE (1996), trabalhando com espécie carnívora, relataram observações semelhantes. 
SEIXAS FILHO et al.

Tabela 1 - Médias do comprimento total, das alças e do calibre dos intestinos médio e posterior e do coeficiente intestinal (CI) da piracanjuba, Brycon orbignyanus

Table 1 - Average of the total length, rings and gauge of the medium and posterior intestines and the intestinal coefficient of piracanjuba (Brycon orbignyanus)

\begin{tabular}{|c|c|c|c|c|c|c|c|}
\hline \multirow{2}{*}{$\begin{array}{l}\text { Classe } \\
\text { Class }\end{array}$} & \multirow{2}{*}{$\begin{array}{l}\text { Alça } \\
\text { Ring }\end{array}$} & \multicolumn{2}{|c|}{$\begin{array}{c}\text { Comprimento } \\
\text { Length }\end{array}$} & \multirow{2}{*}{$\begin{array}{c}\text { Classe } \\
\text { Class }\end{array}$} & \multirow{2}{*}{$\begin{array}{l}\text { Alça } \\
\text { Ring }\end{array}$} & \multicolumn{2}{|c|}{$\begin{array}{c}\text { Comprimento } \\
\text { Length }\end{array}$} \\
\hline & & $\begin{array}{ll} & \text { Ler } \\
(\mathrm{mm}) & \end{array}$ & $(\%)$ & & & $\begin{array}{l}\text { Leng } \\
(\mathrm{mm})\end{array}$ & $(\%)$ \\
\hline \multirow[t]{2}{*}{1} & $\begin{array}{c}1 \\
2 \\
3 \\
4 \\
5 \\
6 \\
7 \\
8 \\
9 \\
\text { Total } \\
\text { CV }\end{array}$ & $\begin{array}{l}6,88( \pm 0,64)^{\mathrm{Bf}} \\
36,61( \pm 3,69)^{\mathrm{Bb}} \\
13,57( \pm 1,16)^{\mathrm{Bd}} \\
8,14( \pm 1,04)^{\mathrm{Bcf}} \\
14,63( \pm 1,34)^{\mathrm{Bd}} \\
16,78( \pm 1,96)^{\mathrm{Bcd}} \\
10,21( \pm 1,28)^{\mathrm{Bde}} \\
17,47( \pm 1,16)^{\mathrm{Abc}} \\
68,77( \pm 1,82)^{\mathrm{Ba}} \\
193,06( \pm 11,14)^{\mathrm{B}} \\
5,77\end{array}$ & $\begin{array}{r}3,56 \\
18,96 \\
7,03 \\
4,22 \\
7,98 \\
8,69 \\
5,29 \\
9,05 \\
35,62 \\
100,00\end{array}$ & 2 & $\begin{array}{l}1 \\
2 \\
3 \\
4 \\
5 \\
6 \\
7 \\
8 \\
9\end{array}$ & $\begin{array}{l}9,26( \pm 0,67)^{\mathrm{Ade}} \\
48,33( \pm 3,57)^{\mathrm{Ab}} \\
18,23( \pm 1,56)^{\mathrm{Ac}} \\
13,67( \pm 0,94)^{\mathrm{Ad}} \\
19,49( \pm 2,56)^{\mathrm{Ac}} \\
22,87( \pm 3,41)^{\mathrm{Abc}} \\
14,60( \pm 1,09)^{\mathrm{Acd}} \\
18,69( \pm 1,50)^{\mathrm{Ac}} \\
103,94( \pm 3,24)^{\mathrm{Aa}} \\
269,10( \pm 9,96)^{\mathrm{A}} \\
3,70\end{array}$ & $\begin{array}{r}3,45 \\
17,96 \\
6,77 \\
5,08 \\
7,25 \\
8,50 \\
5,42 \\
6,95 \\
38,62 \\
100,00\end{array}$ \\
\hline & & $\begin{array}{l}\text { Calibre } \\
\text { Gauge }\end{array}$ & & & & $\begin{array}{l}\text { Calibre } \\
\text { Gauge }\end{array}$ & \\
\hline \multirow[t]{3}{*}{1} & $\begin{array}{c}1 \\
2 \\
3 \\
4 \\
5 \\
6 \\
7 \\
8 \\
9 \\
\text { Média } \\
\text { Mean } \\
\text { CV }\end{array}$ & $\begin{array}{l}2,87( \pm 0,21)^{\mathrm{Ba}} \\
2,77( \pm 0,22)^{\mathrm{Aa}} \\
2,52( \pm 0,25)^{\mathrm{Aa}} \\
2,49( \pm 0,29)^{\mathrm{Aa}} \\
2,56( \pm 0,27)^{\mathrm{Aa}} \\
2,70( \pm 0,33)^{\mathrm{Aa}} \\
2,61( \pm 0,23)^{\mathrm{Aa}} \\
2,39( \pm 0,19)^{\mathrm{Ba}} \\
2,35( \pm 0,23)^{\mathrm{Ba}} \\
2,59( \pm 0,22)^{\mathrm{A}}\end{array}$ & $\begin{array}{r}100,00 \\
96,51 \\
87,80 \\
86,76 \\
89,20 \\
94,08 \\
90,94 \\
83,27 \\
81,88 \\
-\end{array}$ & 2 & $\begin{array}{l}1 \\
2 \\
3 \\
4 \\
5 \\
6 \\
7 \\
8 \\
9\end{array}$ & $\begin{array}{l}3,64( \pm 0,18)^{\mathrm{Aa}} \\
3,03( \pm 0,09)^{\mathrm{Ab}} \\
2,88( \pm 0,08)^{\mathrm{Ac}} \\
2,79( \pm 0,09)^{\mathrm{Ad}} \\
2,58( \pm 0,11)^{\mathrm{Ade}} \\
2,47( \pm 0,10)^{\mathrm{Ae}} \\
2,80( \pm 0,08)^{\mathrm{Acd}} \\
2,92( \pm 0,07)^{\mathrm{Abc}} \\
2,77( \pm 0,10)^{\mathrm{Ad}} \\
2,88( \pm 0,08)^{\mathrm{A}}\end{array}$ & $\begin{array}{r}100,00 \\
83,24 \\
79,12 \\
76,65 \\
70,88 \\
67,86 \\
76,92 \\
80,22 \\
76,10 \\
-\end{array}$ \\
\hline & \multicolumn{6}{|c|}{$\begin{array}{l}\text { Coeficiente intestinal (CI) } \\
\text { Intestine coefficient }\end{array}$} & \\
\hline & Comp & $\begin{array}{l}\text { ento do intestino } \\
(\mathrm{cm}) \\
\text { stine length }\end{array}$ & $\mathrm{Co}$ & $\begin{array}{l}\text { imento- } \\
(\mathrm{cm}) \\
\text { adard len } \\
\end{array}$ & & $\begin{array}{c}\text { Valor do coeficiente } \\
\text { intestinal } \\
\text { Intestine coefficient value }\end{array}$ & $\mathrm{CV}$ \\
\hline 1 & & 18,84 & & 16,13 & & $1,17^{\mathrm{a}}$ & 6,48 \\
\hline 2 & & 26,91 & & 26,15 & & $1,03^{\mathrm{a}}$ & 3,21 \\
\hline
\end{tabular}

Em cada linha, $A>B$ pelo teste $t(P<0,05)$.

Médias, na coluna, seguidas de diferentes letras minúsculas são diferentes pelo teste $t(P<0,05)$.

In each row, $A>B$ by $t$ test.

Means, within a column, followed by different capital letters are different by $t$ test $(P<.05)$.

Tabela 2 - Médias do comprimento e calibre dos cecos pilóricos do intestino médio da piracanjuba (Brycon orbignyanus)

Table 2 - Average of lenght and gange of piracanjuba (Brycon orbignyanus) medium intestine piloric cecum

\begin{tabular}{lcccc}
\hline $\begin{array}{l}\text { Classe } \\
\text { Class }\end{array}$ & $\begin{array}{c}\text { Comprimento-padrão } \\
(\mathrm{cm})\end{array}$ & $\begin{array}{c}\text { Peso }(\mathrm{g}) \\
\text { Weight }\end{array}$ & \multicolumn{2}{c}{$\begin{array}{c}\text { Cecos pilóricos } \\
\text { Piloric cecum }\end{array}$} \\
\cline { 3 - 5 } & Standard length & & $\begin{array}{c}\text { Comprimento }(\mathrm{mm}) \\
\text { Length }\end{array}$ & $\begin{array}{c}\text { Calibre }(\mathrm{mm}) \\
\text { Gauge }\end{array}$ \\
\hline 1 & $14,00 \mathrm{a} 18,00$ & 42,17 a 133,51 & $6,62( \pm 0,43)^{\mathrm{B}}$ & $0,66( \pm 0,55)^{\mathrm{B}}$ \\
\hline $\mathrm{CV}$ & & 6,49 & 7,57 \\
2 & $23,50 \mathrm{a} 29,00$ & 295,34 a 500,60 & $7,63( \pm 0,20)^{\mathrm{A}}$ & $0,82( \pm 0,05)^{\mathrm{A}}$ \\
\hline $\mathrm{CV}$ & & & 2,62 & 6,10
\end{tabular}

Médias, na linha, seguidas de letras diferentes são diferentes pelo teste $t(P<0,05)$.

CV - Coeficiente de variação.

Means, within a row, followed by different letters are different by $t$ test $(P<.05)$.

CV - Coefficient of variation. 


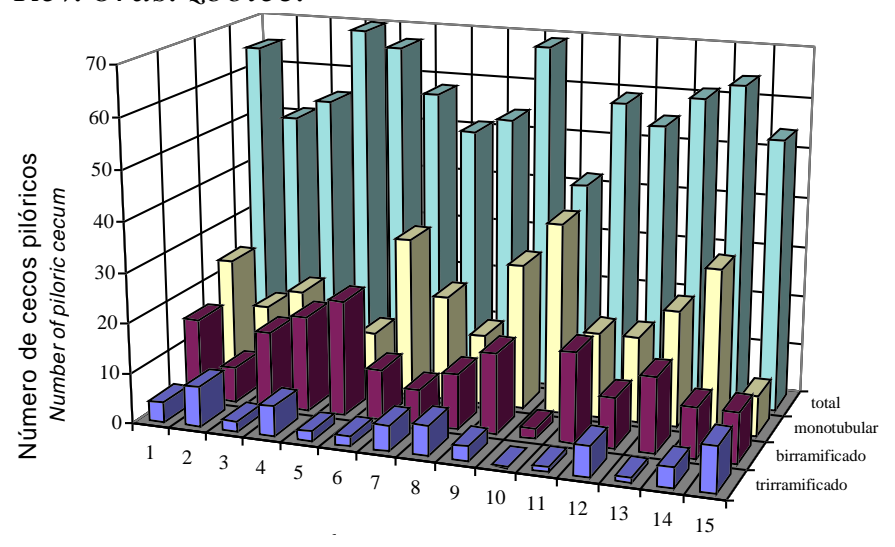

Exemplar de Brycon orbignyanus (classse 1)

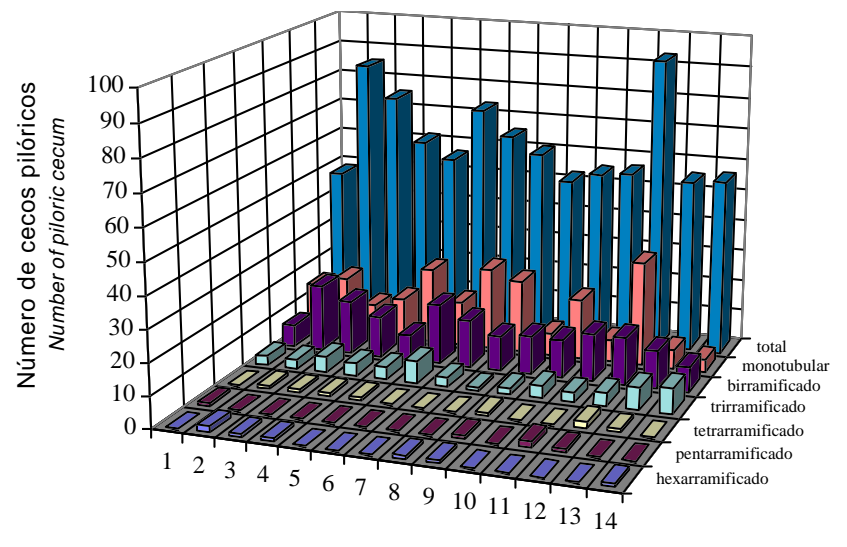

Exemplar de Brycon orbignyanus (classse 1)

Figura 6 - Número de cecos pilóricos nas formas digitiforme, bifurcado, trifurcado, tetrafurcado, pentafurcado e hexafurcado, em relação ao total de cecos pilóricos, nos exemplares da piracanjuba (Brycon orbignyanus), da primeira (A) e da segunda (B) classes de tamanho.

Figure 6 - Number of piloric cecum in the digitiform, forked, triforked, tetraforked, pentaforked and hexaforked, on the total piloric cecum, in the piracanjuba (Brycon orbignyanus) species of the first $(A)$ and second $(B)$ size classes.

Os resultados do comprimento e calibre dos cecos pilóricos no intestino médio encontram-se na Tabela 2. Na primeira classe de tamanho, verificaram-se médias de comprimento e calibre dos cecos pilóricos de 6,62 e $0,66 \mathrm{~mm}$, respectivamente. Os exemplares da segunda classe apresentaram 7,63 e $0,82 \mathrm{~mm}$ de comprimento e calibre, respectivamente, sendo significativamente maiores $(\mathrm{P}<0,05)$ que os anteriores.

No presente estudo, constatou-se que o comprimento e o calibre dos cecos pilóricos aumentaram com o desenvolvimento do peixe, comportando-se de forma semelhante ao crescimento do intestino. Cabe mencionar que a relação entre o comprimento do ceco pilórico e o seu diâmetro é de aproximadamente $10 \%$. Vários são os números e as formas que os cecos pilóricos podem apresentar nas diferentes espécies (JONHNSON, 1907; SUYEHIRO, 1942; RAHIMULLAH, 1945; KHANNA, 1961; MENIN, 1988; FUGI e HAHN, 1991; e LOGATO, 1995).

Quanto ao número de cecos pilóricos encontrados, pode-se observar que, para a primeira classe de tamanho foram encontrados de 42 a 70 cecos pilóricos e nos da segunda, variação de 48 a 93.

Quanto à morfologia, os exemplares da primeira classe de tamanho mostraram esses apêndices na forma cilíndrica, bifurcada e trifurcada. Para os da segunda classe, as formas foram digitiforme, bifurcada, trifurcada, tetrafurcada, pentafurcada e hexafurcada (Figura 6).

Verificou-se que a forma digitiforme esteve presente em maior percentagem para os exemplares da primeira classe de tamanho e as formas bi e trifurcada apresentaram porcentagens semelhantes para as duas classes de tamanho. Estes resultados não apresentaram relação com o comprimentopadrão e o peso dos animais.

O comprimento total dos intestinos médio e posterior aumentou da primeira para a segunda classe de tamanho, e o coeficiente intestinal, que estabelece a relação entre o comprimento total do intestino e o comprimento-padrão dos exemplares pertencentes às classes de tamanho $1 \mathrm{e} 2$, não diferiu significativamente $(\mathrm{P}>0,05)$ (Tabela 1$)$.

O valor médio do coeficiente intestinal dos exemplares da piracanjuba, de $1,17( \pm 0,08)$ e $1,03( \pm 0,03)$ para as primeiras e segundas classes de tamanho, respectivamente, está condizente com a amplitude de valores proposta por BÉRTIN (1958) para o hábito alimentar onívoro, que variou de 0,6 a 8,0. Esses resultados demonstram que o crescimento do intestino acompanha proporcionalmente o comprimento-padrão.

\section{Conclusões}

O padrão de enrolamento das alças intestinais da piracanjuba sugere adaptação para uma alimentação com valores intermediários entre o arranjo intestinal de peixes carnívoros e o dos herbívoros, confirmado pela morfometria e pelo valor do coeficiente intestinal.

Os estudos da morfometria mostraram que o comprimento total do intestino e das alças intestinais 
e seus calibres, provavelmente, exercem função específica na absorção de nutrientes.

As relações entre o arranjo das pregas mucosas e a velocidade de transporte do alimento no intestino médio da piracanjuba sugerem que os padrões transversal e oblíquo retardam o avanço do alimento em sentido aboral, com maior aproveitamento dos nutrientes.

A morfometria dos cecos pilóricos mostrou que o seu crescimento está diretamente relacionado com o do peixe. As características anatômicas das pregas da mucosa dos cecos pilóricos sugerem função de absorção.

\section{Referências Bibliográficas}

ANGELESCU, V., GNERI, F.S. 1949. Adaptaciones del aparato digestivo al régimen alimenticio in algunos peces del rio Uruguay e del rio de la Plata. Rev. Inst. Invest. Mus. Argent. Cienc. Nat., 1:161-272.

AMARAL, A.A. 1990. Anatomia comparativa do aparelho digestório de Acestrorhyncchus britskii Menezes, 1969, e Acestrorhyncchus lacustris (Reinhardti, 1874) (Piscces, Characidae, Acestrorhynchinae). Rev. Ceres, 37:227-288.

AMLACHER, E. 1964. Manual de enfermidades de los peces. Zaragosa, Editorial Acribia. 319p.

BÉRTIN, L. 1958. Appareil digestif. In: GRASSÉ, P.P. (Ed.). Traité de zoologie. Paris: Masson, v.13 p.1249-1301.

BISHOP, C., ODENSE, P.H. 1966. Morphology of the digestive tract of the cod Gadus morhua., J. Fis. Res. Bd. Can., 23:1607-1615.

BURNSTOCK, G. 1959. Morphology of the gut of the brown trout (Salmo trutta). Quart. J. Microsc. Sci., 100:183-198.

CHAUDRY, H.S., KHANDELWAL, O.P. 1961. The anatomy and histology of the alimentary tract of Oreinus plagiostomus. Ann. Zool. Jap., 34:134-152.

CYRINO, J.E.P. Digestibilidade da proteína de origem animal e vegetal pelo matrinxã, Brycon cephalus, GÜNTHER, 1869 (Teleostei, Characoidei, Caracidae). Manaus, AM: INPA/ FUA, 1984. 39p. Dissertação (Mestrado em Biologia de Água Doce e Pesca Interior) - Instituto Nacional de Pesquisa da Amazônia, 1984.

FUGI, R., HAHN, N.S. 1991. Espectro alimentar e relações morfológicas com o aparelho digestório de três espécies de peixes comedores de fundo do rio Paraná, Brasil. Rio de Janeiro, Rev. Bras. Biol., 51:873-879.

GALLEGO, M.G., RUS, A.S. 1987. Absórcion intestinal en peces. In: ESPINOSA DE LOS MONTEROS, J., LABARTA, U.(Eds.). Nutricion en acuicultura I. Madrid: Plan de Formación de Técnicos Superiores en Acuicultura. p.123-171.

GOMIDE, A.T.M. Anatomia funcional, e morfometria comparativas do tubo digestório de trairão (Hoplias cf. lacerdae RIBEIRO, 1908) (CHARACIFORMES, ERYTHRINIDAE), em diferentes classes de tamanho. Viçosa, MG: UFV. 1996. 76p. Dissertação (Mestrado em Zootecnia) - Universidade Federal de Viçosa, 1996.

HIDALGO, F., ALLIOT, E. 1987. La digestión en los peces. In: ESPINOSA DE LOS MONTEROS, J., LABARTA, U. (Eds.). Nutrición en acuicultura I. Madrid: Plan de Formación de Técnicos Superiores en Acuicultura. p.85-107.
JONHSON, R.H. 1907. The individuality and variation of the pyloric caeca of the centrarchidae. Wisconsin Acad. of Sci., Arts, and Letters, 15:713-733.

KAPOOR, B.G., SMIT, H., VERGHINA, I.A. 1975. The alimentary canal and digestion in fish. Advances in Marine Biology, 13:109-239.

KHANNA, S.S. 1961. Alimentary canal in some Teleoste an fishes. J. Zool. Soc. India, 13:206-219.

LOGATO, P.V.R. Anátomo-histologia funcional do aparelho digestório do pacu, Piaractus mesopotamicus Holmberg, 1887 (Characiformes, Characidae, Myelinae). Viçosa, MG: UFV, 1995. 118p. Tese (Doutorado em Zootecnia) - Universidade Federal de Viçosa, 1995.

MAGNAN, P., STEVENS, E.D. 1993. Pyloric caecal morphology of brook charr, salvelinus fontinalis, in relation to diet. Guelph. Env. Biol. Fishes., 36:205-210.

MENIN, E. Anátomo-histologia funcional comparativa do aparelho digestório de seis Teleostei (Pisces) de água doce. São Paulo, SP: USP, 1988. 557p. Tese (Doutorado em Anátomofisiologia) - Universidade de São Paulo, 1988.

MENIN, E. 1994. Fisiologia animal comparada. Viçosa, MG: Imprensa UFV. 188p. (Manual de laboratório, 347)

MORAES, M.F.P.G., BARBOLA, I.F., GUEDES, E.A.C. 1997. Alimentação e relações morfológicas com o aparelho digestório do "curimbatá", Prochilodus lineatus (Valenciennes) (Osteichthyes, Prochilodontidae), de uma lagoa do sul do Brasil. R. Bras. Zoologia, 14:169-180.

PEZZATO, L.E. O estabelecimento das exigências nutricionais das espécies de peixes cultivadas. In: SIMPÓSIO SOBRE MANEJO E NUTRIÇÃO DE PEIXES. São Paulo, 1997. Anais... Piracicaba: CBNA, 1997, p.45-62.

RAHIMULLAH, M. 1945. A comparative study of the morphology, histology and probable functions of the pyloric caeca, in Indian fishes, together with discussion on their homology. Proc. Ind. Acad. Sci., 21B:1-37.

RICKER, W.E. 1968. Methods for assessment of fish production in fresh waters. Oxford: Blackwell Scientific Publications. 313p.

SINHA, G.M., MOITRA, S.K. The comparative histology of the alimentary canal of Cirrhina reba (Ham.) during the different stages of life history in relation to food and feeding habits. In: INDIAN SCIENCE CONGRESS, 59, 1972, Bangladesh. Proceedings... Bangladesh: ISAS, 1972, p. 464.

SINHA, G.M., MOITRA, S.K. 1975a. Functional morphohistology of the alimentary canal of an Indian freshwater major carp Labeo rohita (Ham.) during its different lifehistory stages. Anat. Anz., 138:222-239.

SINHA, G.M., MOITRA, S.K. 1975b. Morpho-histology of the intestine in a freshwater major carp, Cirrhinus mrigala (Hamilton) during the different life-story stages in relation to food and feeding habits. Anat. Anz. Bd., 137S:395-407.

SUYEHIRO, Y.A. 1942. Study of the digestive system and feeding habits of fish. Jap. J. Zool., 10:1-303.

YABE, R.S., BENNEMANN, S.T. 1997. Regime alimentar de Schizodon intermedius, Garavello e Britski do Rio Tibagi, Paraná, e sua relação com algumas características morfológicas do trato digestivo (Osteichthyes, Anostomidae). Rev. Bras. Zool., 14:777-788.

Recebido em: 10/05/99 Aceito em: 10/11/99 